\title{
Expression of MUC1 mucin in human umbilical vein endothelial cells (HUVEC)
}

\section{Halina Porowska ${ }^{1}$, Anna Paszkiewicz-Gadek ${ }^{1}$, Joanna Wosek ${ }^{1}$, Krzysztof Wnuczko² Malgorzata Rusak ${ }^{3}$ and Marek Szczepański ${ }^{2}$}

\author{
${ }^{1}$ Department of Medical Chemistry, \\ ${ }^{2}$ Department of Neonatology, \\ ${ }^{3}$ Department of Hematological Diagnostics, Medical University of Białystok, Białystok, Poland
}

\begin{abstract}
Mucin 1 (MUC1) is a membrane-bound glycoprotein that is expressed by various epithelial cell types. MUC1 functions include modulation of cell adhesion, signal transduction, lubrication and hydration of epithelial surfaces, and their protection from infection. In this study we demonstrated that MUC1 is expressed in human umbilical vein endothelial cells (HUVECs) and could be released/shed from cellular membrane. MUC1 presence in these cells was verified using three methods: Western blotting, flow cytometry and metabolic labeling. We also showed that mucin expression is stimulated by proinflammatory cytokines: about a 2 -fold increase was observed after TNF- $\alpha$ treatment and lower after IFN- $\gamma$ alone and in combination with TNF- $\alpha$ treatment. It can be assumed that the presence of MUC1 in endothelial cells may have an important role in the interactions with different cell types in physiological and pathological processes.
\end{abstract}

Key words: MUC1 mucin, cytokines, HUVEC

\section{Introduction}

Mucins are high molecular mass O-glycosylated proteins $(50-80 \%$ of their mass is due to O-linked carbohydrate chains) which can be divided into membrane bound and secreted [1]. They are expressed by various epithelial cell types having a central role in the protection, lubrication and acid resistance of the epithelial surface and, therefore, in promoting cell survival in variable conditions. However, alterations in mucins expression profile have been long implicated in several animal and human diseases, especially in malignant transformation. At least nineteen mucin genes have been reported to date. The secretory mucins include MUC2, MUC5B, MUC5AC, MUC6, MUC7, MUC8, MUC9 and MUC19 while the membrane bound comprise MUC1, MUC3A, MUC3B, MUC4, MUC12, MUC13, MUC15, MUC16, MUC17 and MUC20 [2-4].

MUC1 is a transmembrane mucin expressed on the apical surface of most epithelia. Full length MUC1 is synthesized as a single polypeptide chain, which

Correspondence: H. Porowska, Dept. of Medical Chemistry, Mickiewicza Str. 2a, 15-222 Bialystok, Poland; tel.: (+4885) 7485672, e-mail: zachemog@umwb.edu.pl undergoes an early proteolytic cleavage, creating two subunits that remain associated during its post-translational processing and transport to the cell surface [5]. Supposedly, the heterodimeric existence of MUC1 may provide a mechanism for rapid shedding of the extracellular domain [1]. The large fragment contains most of the extracellular domain while the smaller subunit consists of a short extracellular domain, a transmembrane domain and a tyrosine-phosphorylated cytoplasmic tail (CT) of 72 aminoacids $[1,5,6]$. The proposed functions for MUC1 include modulation of cell adhesion, signal transduction in which $\mathrm{CT}$ is involved, lubrication and hydration of epithelial surfaces as well as their protection from infection [7-10].

Although the expression of transmembrane mucins was originally thought to be restricted to epithelial tissues, in a recent study MUC4 was detected in three types of endothelial cell lines, among others of HUVECs [11]. Additionally, the expression of MUC1 mRNA was observed by RT-PCR in the human corneal endothelium, like MUC1 protein, on the apical surface of these cells and at the superficial layer of the cytoplasm in an immunohistochemical study [12]. MUC1 mRNA and protein expression was also find in pulmonary vascular endothelial cells [13]. Our preliminary 
experiments indicated the presence of MUC1 glycoprotein in culture medium of HUVE cells. As we were surprised to find MUC1 protein expression in endothelial cells, we decided to investigate transmembrane MUC1 mucin biosynthesis in human umbilical vein endothelial cells (HUVECs) in culture. Since up to now there have been only a few publications concerning MUC1 mucin expression in endothelial cells, we examined this expression using three different methods: Western blotting, flow cytometry and quantitative measurement of incorporated radioactivity. The presence of MUC1 on the surface of HUVE cells, and the possible participation of carbohydrate epitopes of MUC1 as ligands on this surface have not been yet demonstrated.

\section{Materials and methods}

Materials. [6- $\left.{ }^{3} \mathrm{H}\right]-$ Glucosamine hydrochloride (specific activity $24 \mathrm{Ci} / \mathrm{mmol} ; 888 \mathrm{GBq} / \mathrm{mmol}$ ) was from PerkinElmer Life Sciences, Inc. TNF- $\alpha$, IFN- $\gamma$, collagen I, SDS, protease inhibitor cocktail, secondary antibody conjugated with horseradish peroxidase, 4-chloro-1-naphtol, ABTS liquid substrate system, trypan blue, culture media were purchased from Sigma-Aldrich Co. (USA). Monoclonal anti-MUC1 antibody (clone MAb 4058) was from Chemicon International; monoclonal anti- $\beta$-actin antibody was the product of Santa Cruz Biotechnology Inc. Monoclonal anti-MUC1 antibody conjugated with fluorescein isotiocyanate (HMPV-FITC), IgG1-FITC isotype control and fibronectin-coated 96-well plates were purchased from BD Pharmingen; Immobilon$\mathrm{P}$ membrane was from Millipore (USA); 25 and $75 \mathrm{~cm}^{2}$ culture flasks coated with fibronectin were from Nalge Nunc International Inc. (USA) and 96-well microtitre plates were from Nunc (Denmark); BCA Protein Assay Kit was from Pierce (USA). Polyacrylamide gradient gels $4-12 \%$ were from Lonza. Biotinylated lectins (Maccia amurensis -MAA and Arachis hypogaea -PNA) and streptavidin-HRP conjugate were from Vector Labs. EC10 blocker of $\alpha 2 \beta 1$ integrin and VLO4 disintegrin, specibfic inhibitor of $\alpha 5 \beta 1$ integrin, were kindly provided by Dr. C. Marcinkiewicz from Temple University (Philadelphia, USA). All other chemicals were of analytical grade purity from commercial sources.

Cell cultures. Endothelial cells were isolated from human umbilical vein by treatment with collagenase $(1 \mathrm{mg} / \mathrm{ml})$ for $10 \mathrm{~min}$ at $37^{\circ} \mathrm{C}$ and the obtained suspension was then centrifuged at 2,500 rpm for $10 \mathrm{~min}$ at room temperature. The cells were cultured in 75 $\mathrm{cm}^{2}$ flasks coated with fibronectin, in M199 medium supplemented with $20 \%$ fetal bovine serum, penicillin G (100 IU/ml), streptomycin $(100 \mu \mathrm{g} / \mathrm{ml})$, amphotericin B $(0.25 \mu \mathrm{g} / \mathrm{ml})$, heparin $(100$ $\mu \mathrm{g} / \mathrm{ml})$, ECGS $(200 \mu \mathrm{g} / \mathrm{ml})$ and Hepes $(25 \mathrm{mmol} / \mathrm{l})$ at $37^{\circ} \mathrm{C}$ in a $5 \%$ $\mathrm{CO}_{2}$ and $95 \%$ air incubator. Subconfluent cells (above $90 \%$ of confluency) were detached with $0.1 \%$ trypsin in serum-free M199 medium, counted and inoculated at about $10^{6}$ cells per $25 \mathrm{~cm}^{2}$ flask. The HUVEC cultures were characterized by differential immunocytochemical staining to confirm their purity. More than $95 \%$ of the cells stained positively with antibodies against von Willebrand factor. The cells within 3-4 passages were used for the experiments. After reaching $80 \%$ of confluence, the cells were treated with one of the following: TNF- $\alpha(40 \mathrm{ng} / \mathrm{ml})$ or IFN- $\gamma(40$ $\mathrm{ng} / \mathrm{ml}$ ); or TNF- $\alpha$ together with IFN- $\gamma$ (both at $40 \mathrm{ng} / \mathrm{ml}$ ) for $48 \mathrm{~h}$. In some experiments, labeling with $\left[{ }^{3} \mathrm{H}\right]$ glucosamine $(20$ $\mu \mathrm{Ci} /$ flask) was performed during the last $24 \mathrm{~h}$ when cells were destined for quantitative determination of MUC1 mucin.
Preparation of cell lysates and culture media. The cell layer was washed with phosphate buffered saline (PBS), harvested by scraping and centrifuged (4,000 rpm, $10 \mathrm{~min})$. The media and cell washings were combined for determination of MUC1 shedding level. MUC1 mucin was isolated from culture media by exclusion chromatography on Bio-Gel A- $0.5 \mathrm{~m}$ column, as previously described [14]. The cells were homogenized in an ice bath using sonification (3 times for $15 \mathrm{sec} ; 50 \mathrm{~Hz}$ ) in $0.5 \mathrm{ml}$ of lysis buffer $(50 \mathrm{mM}$ Tris/HCl $\mathrm{pH} 7.5$, containing $1 \mathrm{mM}$ EDTA and protease inhibitor cocktail), then $0.5 \mathrm{ml}$ of lysis buffer, containing Nonidet P-40, was added (final concentration of detergent was $1 \%$ ). The homogenate was incubated in an ice bath for $1 \mathrm{~h}$, centrifuged at 16,000 rpm for $30 \mathrm{~min}$, and the supernatant was used as lysate for further determinations. Cells for the adhesion test were harvested using a different method described below.

Protein concentration in culture media and cell lysates was determined by the bicynchonic acid method according to the manufacturer's description.

SDS-PAGE and Western blotting. Equal amounts of cellular protein $(30-50 \mu \mathrm{g})$ were submitted to electrophoresis on gradient SDSpolyacrylamide gels $(4-12 \%)$, according to the Laemmli method [15]. Pre-stained high molecular weight protein markers (range 29,000-205,000 Da) were used as standards. After electrophoresis, the proteins were electrotransferred onto PVDF membranes (Immobilon-P) in a buffer consisting of $25 \mathrm{mM}$ Tris, $192 \mathrm{mM}$ glycine and $20 \%$ methanol, $\mathrm{pH} 8.4$, for $2 \mathrm{~h}$ at constant voltage (100 V) with cooling. Membranes were blocked with 3\% skim milk overnight, then incubated with anti-MUC1 MAb (MAb 4058, 1:500) for $2 \mathrm{~h}$. Membranes were washed and incubated with antimouse IgG antibody conjugated with peroxidase, then color was developed by the use of 4-chloro-1-naphtol reagent.

Quantitative determination of MUC1 by measurement of incorporated $\left[{ }^{3} \mathbf{H}\right]$ glucosamine. The lysates of metabolically labeled cells were submitted to exclusion chromatography on BioGel A- $0.5 \mathrm{~m}$ columns as previously described [14]. The concentrated high molecular weight fraction of cell lysates was separated by SDS-PAGE and then quantitative determination of MUC1 radioactivity was performed according to Yan i Sohal [16]. The fragments of gel, equivalent to respective protein lanes, were cut onto $1.0 \mathrm{~cm}$ wide pieces. Each of them was dried, dissolved in $1 \mathrm{ml}$ of $30 \%$ $\mathrm{H}_{2} \mathrm{O}_{2}$ and the radioactivity of $\left[{ }^{3} \mathrm{H}\right]$ was measured in a scintillation counter.

Cell-surface ELISA. Human umbilical vein endothelial cells (HUVEC) ELISA was performed according to the method described by Strindhall et al. [17], with some modifications. Briefly, cells were grown in M199 medium in 96-well microtitre plates to a confluent cobblestone-like monolayer, and then incubated with TNF- $\alpha(40 \mathrm{ng} / \mathrm{ml})$ for different periods of time $(0,2,6$ and $18 \mathrm{~h}$ ). They were washed once with PBS and fixed with $0.1 \%$ formaldehyde/PBS for $10 \mathrm{~min}$ at room temperature. After two washes with PBS, the cells were incubated with $\mathrm{PBS} / 5 \%$ BSA for $1 \mathrm{~h}$ at room temperature or overnight at $4^{\circ} \mathrm{C}$ to block nonspecific binding sites. The cells were washed once with PBS $/ 0.05 \%$ Tween 20 and once with PBS and then incubated with anti-MUC1 primary antibody (MAb 4058) at a 1:400 dilution in PBS/1\% BSA for $2 \mathrm{~h}$ at $37^{\circ} \mathrm{C}$ with gentle rocking. Then, they were washed twice with PBS and once with PBS $/ 0.05 \%$ Tween 20 and incubated with secondary antibody conjugated with horseradish peroxidase at a dilution of $1: 1000$ in PBS/1\% BSA for $2 \mathrm{~h}$ at room temperature with gentle rocking. Detection was performed by using ABTS reagent as a substrate. Color development was measured as the absorbance at $405 \mathrm{~nm}$ using ELISA-reader (Sunrise, Tecan).

Some carbohydrate structures on HUVECs were detected by ELLA (enzyme-linked lectin assay) which was performed as above 


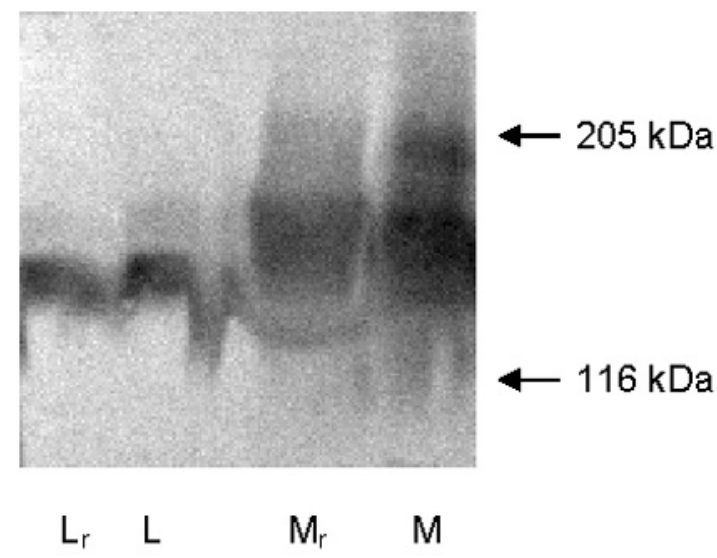

Fig. 1. Detection of MUC1 in lysate and medium of HUVEC. Cells were cultured for $48 \mathrm{~h}$ then medium and lysate were electrophoresed on $4-12 \%$ polyacrylamide gradient gels (Lonza), electrotransfered onto PVDF membrane and immunodetected with anti-MUC1 antibody (MAb 4058, 1:500). L- lysate; $\mathrm{L}_{\mathrm{r}}$ - lysate in reducing conditions; $\mathrm{M}$-medium; $\mathrm{M}_{\mathrm{r}}$ - medium in reducing conditions.

described, but instead of monoclonal antibodies, biotinylated lectins were used: from Maccia amurensis (MAA) to recognize $\alpha 2,3$ linked sialic acid and from Arachis hypogaea (PNA) to detect T antigen

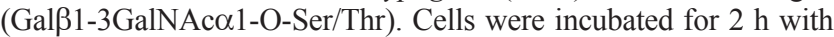
biotinylated-PNA or -MAA, both at $20 \mu \mathrm{g} / \mathrm{ml}$, before being washed and incubated for $1 \mathrm{~h}$ with streptavidin-HRP conjugate at $5 \mu \mathrm{g} / \mathrm{ml}$. The remaining protocol of detection was the same as for the reaction with monoclonal antibody. Before treatment with PNA lectin, the cells were incubated with Vibrio cholerae neuraminidase (15 $\mathrm{mU} / \mathrm{ml}, 1.5 \mathrm{~h}$ ) in order to remove terminal sialic acid residues.

Flow cytometry. Cells were detached from tissue culture flasks with $0.2 \%$ EDTA in PBS, pH 7.4 and washed in PBS containing 1\% BSA and $0.1 \% \mathrm{NaN}_{3}$ (PBS/1\% BSA). To determine MUC1 expression on cell surface, the detached cells were incubated with fluorescein isotiocyanate (FITC)-conjugated mouse anti-human MUC1 monoclonal antibody, according to the method described for Ishikawa cell line in our earlier study [18]. Mouse IgG1-FITC antibody was used as a negative control. After washing, the cells were analyzed for fluorescence intensity by flow cytometry (Coulter Epics XL).

Cell adhesion assay. Adhesion assay was performed with control and TNF- $\alpha$ stimulated cells, according to the method described earlier [18]. Fibronectin coated plates (BD Pharmingen, 96-well) and plates coated with collagen type I $(100 \mu \mathrm{g} / \mathrm{ml})$ were blocked for 90 min at $37^{\circ} \mathrm{C}$ with $1 \%$ heat-denatured BSA. Cells for adhesion assay were scraped off, washed in serum-free medium and re-seeded at a density of $5 \times 10^{4}$ cells/well on collagen or fibronectin. They were allowed to adhere for $60 \mathrm{~min}$ at $37^{\circ} \mathrm{C}$. Non-adherent cells were removed by washing 3 times with PBS, whereas adherent cells were stained with $0.1 \%$ crystal violet for $30 \mathrm{~min}$, washed in tap water and air dried. Stained cells were lyzed overnight in $0.1 \%$ Triton X-100 to release the dye. The absorbance at $620 \mathrm{~nm}$ determined using an ELISA-reader (Sunrise, Tecan) was proportional to cell number. Each data point was calculated from two separate experiments performed in quadruplicate and was expressed as the mean \pm standard deviation (SD). Nonspecific cell adhesion as measured on BSAcoated wells was subtracted.

In order to determine the effect of the inflammatory cytokine on HUVE cells adhesion to ECM proteins (collagen I and fibronectin) the cells were treated for 6 hours with increasing doses (10 and $40 \mathrm{ng} / \mathrm{ml}$ ) of TNF- $\alpha$. Non-treated cells served as a control.
Assay of MUC1 influence on cell adhesion. To test the effect of MUC1 on HUVE cells adhesion to fibronectin or collagen type I, a part of cell suspension was preincubated with anti-MUC1 MAb 4058 (1:25 diluted), and added to each well $\left(5 \times 10^{4}\right.$ cells/well $)$ in quadruplicate. Further procedure was the same as described above for the adhesion test. Results were expressed as a percentage of OD value of cells with antibody in comparison to OD of cells without antibody.

Assay of integrins effect on cell adhesion. To test the effect of $\alpha 5 \beta 1$ integrin on cell adhesion to fibronectin a part of cell suspension was preincubated with VLO4 disintegrin $(2 \mathrm{mg} / 0.1 \mathrm{ml})$, which is a potent and selective in vitro inhibitor of $\alpha 5 \beta 1$ integrin [19], then added to each fibronectin-coated well $\left(5 \times 10^{4}\right.$ cells/well $)$ in quadruplicate. The effect of $\alpha 2 \beta 1$ integrin on cell adhesion to collagen type I was examined in the same conditions with EC10 $(2 \mathrm{mg} / 0.1 \mathrm{ml})$, a specific blocker of this integrin [20]. A further procedure of cell adhesion assay was the same as described above. Results were expressed as a percentage of OD value of cells with antibody in comparison to OD of cells without inhibitor.

Ethical issues. The study was approved by the Committee for Ethics and Supervision on Human and Animal Research, Medical University of Białystok, with informed consent from the patients.

Statistical analysis. The results were subjected to statistical analysis by Statistica 6.0 PL program. Data are represented as mean \pm SD. Normal distribution of data was assessed by the KolmogorovSmirnov test. Since the values met the criteria of a normal distribution the results were submitted to statistical analysis with the use of Student's $t$-test, accepting p 0.05 as significant.

\section{Results}

\section{Western blotting detection of MUC1 in HUVECS}

To probe for the expression of MUC1 mucin in HUVECs, the lysates were obtained by cells sonification, then the incubation with lysing buffer and this material was used for electrophoresis. To test the presence of soluble secreted/shed MUC1 form in the growth medium, the culture medium was concentrated, pre-purified on Bio-Gel A- $0.5 \mathrm{~m}$ column and high molecular weight fraction, dot-blot valuated for MUC1 presence, was used for electrophoresis. Electroblotting and detection of MUC1 antigens with MAb 4058 , specific to tandem repeat core of MUC1 protein, confirmed the presence of MUC1 protein in lysates and medium fractions. As shown in Fig. 1, cellular medium contains MUC1 mucin in greater quantity then lysate, and molecular weight of this protein is higher in medium then in lysate.

\section{Effect of TNF- $\alpha$ and IFN- $\gamma$ on membrane localization of MUC1 on HUVECs}

Earlier studies have shown that MUC1 biosynthesis in multiple epithelial cell types can be stimulated by TNF- $\alpha$ [21]. Therefore, searching for the factors affecting MUC1 expression in endothelial cells, we first applied TNF- $\alpha$. Incubation of HUVECs with 
A

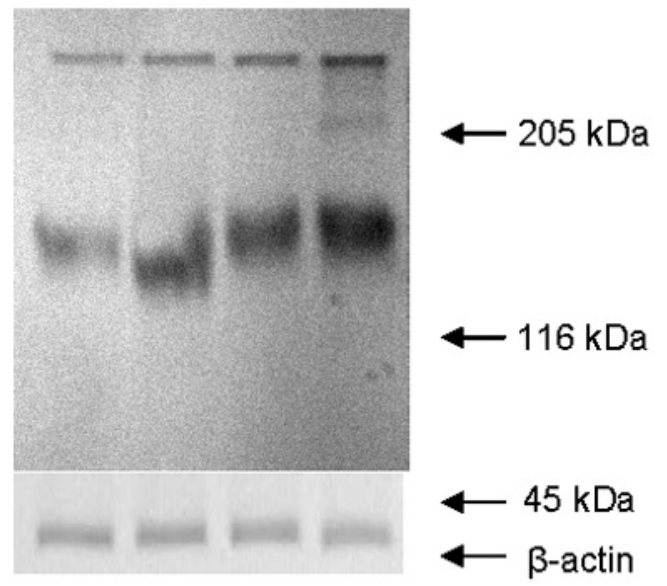

1 $\begin{array}{lll}2 & 3 & 4\end{array}$

\begin{tabular}{|c|c|c|c|c|}
\hline \multirow[b]{2}{*}{ MUC1 } & Lane 1 & Lane 2 & Lane 3 & Lane 4 \\
\hline & \multicolumn{4}{|c|}{$\begin{array}{l}\text { Relative color intensity } \\
\text { of MUC1 bands }\end{array}$} \\
\hline$>205 \mathrm{kDa}$ & 1.0 & $1.8^{*} \pm 0.2$ & $1.3 \pm 0.1$ & $1.65^{*} \pm 0.2$ \\
\hline $116-205 \mathrm{kDa}$ & 1.0 & $1.6^{*} \pm 0.2$ & $1.2 \pm 0.1$ & $1.3 \pm 0.1$ \\
\hline
\end{tabular}

B

\begin{tabular}{|c|c|c|c|c|}
\hline \multirow[b]{2}{*}{ MUC1 } & Lane 1 & Lane 2 & Lane 3 & Lane 4 \\
\hline & \multicolumn{4}{|c|}{$\begin{array}{l}\text { Relative radioactivity } \\
\text { of MUC1 bands }\end{array}$} \\
\hline$>205 \mathrm{kDa}$ & 1.0 & $3.5^{*} \pm 0.5$ & $1.5^{*} \pm 0.2$ & $2.4^{*} \pm 0.5$ \\
\hline $116-205 \mathrm{kDa}$ & 1.0 & $2.2^{*} \pm 0.2$ & $1.2 \pm 0.1$ & $1.5^{*} \pm 0.1$ \\
\hline
\end{tabular}

Fig. 2. The influence of cytokines on MUC1 expression determined by Western blotting and radioactivity measurement. (A) MUC1 expression determined by Western blotting: 1 - control cells (untreated); 2 - cells treated with TNF- $\alpha$ (40 ng/ml); 3 treated with IFN- $\gamma(40 \mathrm{ng} / \mathrm{ml}) ; 4$ - treated with TNF- $\alpha$ together with IFN- $\gamma$ (both at $40 \mathrm{ng} / \mathrm{ml}$ ); MW - high molecular mass protein standards. The cells were incubated with cytokines for $48 \mathrm{~h}$. Values of MUC1 band intensity were measured by the use of SynGene software. The intensity of MUC1 bands from lane 1 (control untreated cells) was assumed as 1.0. The expression of $\beta$-actin served as a control for protein loading. (B) Quantitative determination of MUC1 by measurement of radioactivity in the scraps of polyacrylamide gel. Radioactivity of $\left[{ }^{3} \mathrm{H}\right]$ glucosamine incorporated to MUC1 areas from lane 1 (control untreated cells) was assumed as 1.0 (for details see Material and methods section). Data are shown as means from three independent experiments. ${ }^{*} \mathrm{p}<0.05$, statistically significant differences compared with untreated (control) cells.

TNF- $\alpha(40 \mathrm{ng} / \mathrm{ml})$ at varying time intervals $(2 \mathrm{~h}, 6 \mathrm{~h}$ or $18 \mathrm{~h}$ ) has a small effect on membrane localization of MUC1 protein, which was determined in a test similar to ELISA, with monoclonal antibody (Table 1). In similar test with lectins, specifically reacting with certain carbohydrate structures, the incubation with TNF- $\alpha$ was shown to have no effect on membrane $\mathrm{T}$ antigen
Table 1. Effect of TNF- $\alpha$ on expression of membrane antigens (MUC1, T antigen and $\alpha 2,3$-sialic acid) on HUVECs. HUVECs were incubated with TNF- $\alpha(40 \mathrm{ng} / \mathrm{ml})$ at varying time intervals (2h, 6h, or 18h) and expression of particular structures was evaluated in ELISA test. Values are the mean $\pm \mathrm{SD}$ of three distinct experiments. ${ }^{*}$ The results are significantly different $(\mathrm{p}<0.05)$ from the untreated, control cells taken as $100 \%$.

\begin{tabular}{|c|c|c|c|}
\hline \multirow{2}{*}{ Incubation time (h) } & \multicolumn{3}{|c|}{ \% of control } \\
\cline { 2 - 4 } & MUC1 & T antigen & $\alpha 2,3$-sialic acid \\
\hline 0 & 100 & 100 & 100 \\
\hline 2 & $98 \pm 5$ & $99 \pm 7$ & $92 \pm 6$ \\
\hline 6 & $94 \pm 5$ & $103 \pm 8$ & $84 \pm 5^{*}$ \\
\hline 18 & $105 \pm 5$ & $97 \pm 7$ & $79 \pm 5^{*}$ \\
\hline
\end{tabular}

and resulted in a small decrease in the level of terminal $\alpha 2,3$-linked sialic acid residues (Table 1).

Taking into account the above results, we extended incubation time with TNF- $\alpha$ to $48 \mathrm{~h}$ and, in addition, IFN- $\gamma$ was employed alone and in combination with TNF- $\alpha$. The expression of MUC1, in control untreated cells and in cells treated with cytokines, was probed in three different manners: Western blotting, flow cytometry and metabolic labeling with measurement of gel fragment radioactivity after SDS-PAGE.

Detection of MUC1 antigens in cellular lysates was performed by Western blotting with anti-MUC1 antibody (MAb 4058, specific to tandem repeat core of MUC1 protein). As shown in Fig. 2A, both TNF- $\alpha$ and IFN- $\gamma$ significantly increased MUC1 protein expression in HUVE cells. Two MUC1 forms, with different molecular masses: one exceeding $205 \mathrm{kDa}$ and the other $116 \mathrm{kDa}$ are visible with a little change in band position in the presence of TNF- $\alpha$. The intensity of the bands was quantified by densitometry analysis. As shown by densitometry, about a 2 -fold increase in MUC1 expression was obtained following TNF- $\alpha$ treatment, compared to constitutive MUC1 expression. A smaller increase in MUC1 expression was observed after treatment with IFN- $\gamma$ alone (about 1.3 -fold) and in combination with TNF- $\alpha$ (about 1.5 -fold).

To verify a quantitative assessment of cellular MUC1 protein content and probe for the influence of these cytokines, the cells were labeled with $\left[{ }^{3} \mathrm{H}\right]$-glucosamine. Radioactive labeled macromolecules from cell lysates were analyzed by SDS-PAGE on precast 4$12 \%$ gradient gels. The results obtained in this method confirmed stimulating effect of TNF- $\alpha$ and IFN- $\gamma$ on MUC1 biosynthesis in HUVE cells (Fig. 2B). Based on the results of radioactivity measurement it can be also affirmed that TNF- $\alpha$ significantly increased MUC1 mucin glycosylation, since expression of MUC1 glycoform with high molecular mass above $205 \mathrm{kDa}$ (on the top of gel) was over 3-fold increased, compared with this glycoform from control untreated cells. 


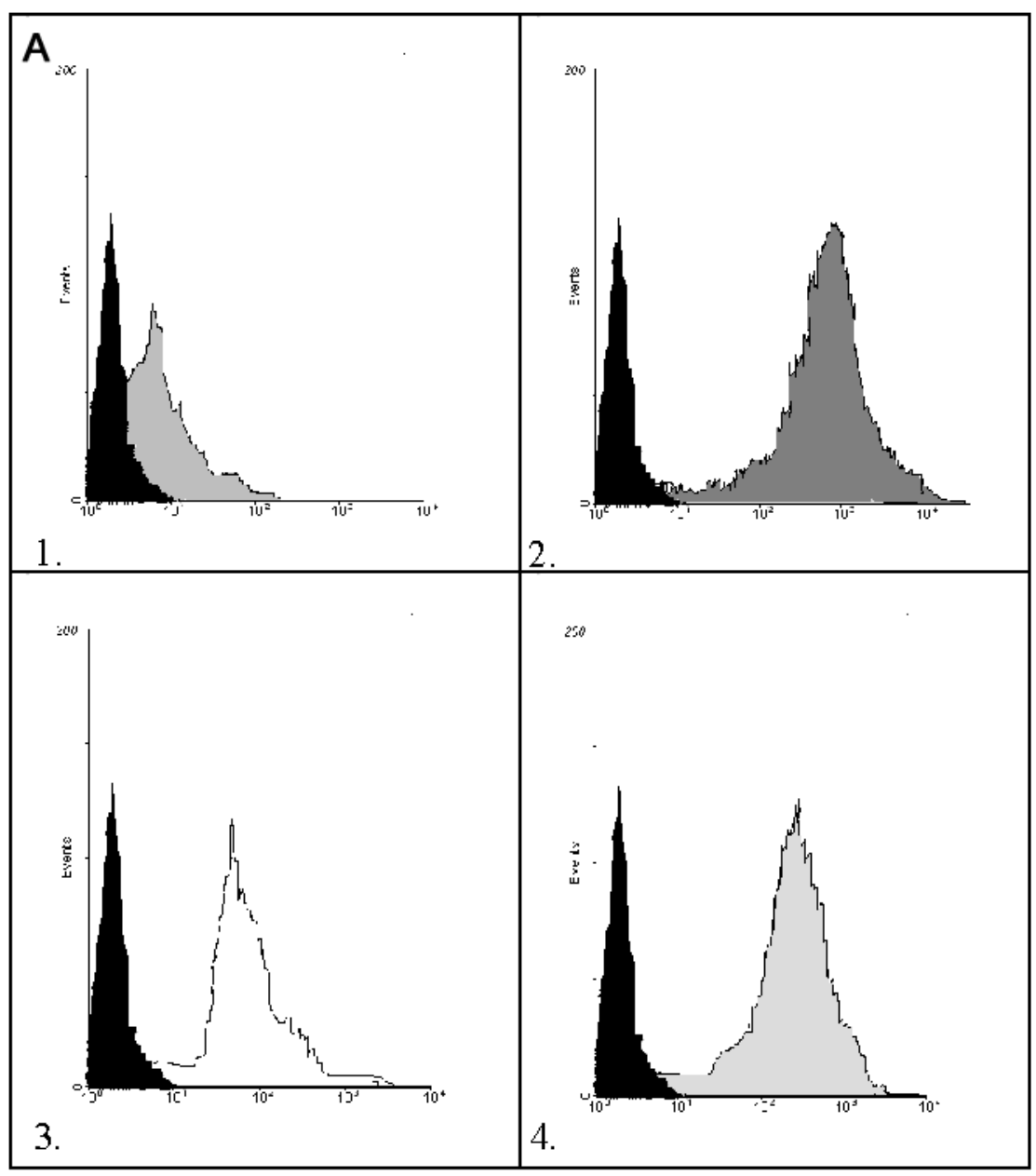

B

\begin{tabular}{|l|c|c|}
\hline \multicolumn{1}{|c|}{ Cell treatment } & MFI & $\%$ \\
\hline Control (untreated) & $25.36 \pm 3.00$ & 100 \\
\hline TNF- $\alpha$ & $59.87^{*} \pm 5.25$ & 236 \\
\hline IFN- $\gamma$ & $38.12^{*} \pm 4.20$ & 150 \\
\hline TNF- $\alpha+\mathrm{IFN}-\gamma$ & $44.67^{*} \pm 5.18$ & 176 \\
\hline
\end{tabular}

Fig. 3. Flow cytometric analysis of cytokine effect on the level of plasma-membranelocalized MUC1 in HUVECs. (A) Representative flow-cytometry profiles (histograms): 1 - control cells (untreated); 2 - TNF- $\alpha$-treated $(40 \mathrm{ng} / \mathrm{ml}) ; 3$ - IFN- $\gamma$-treated $(40 \mathrm{ng} / \mathrm{ml})$; 4 - treated with TNF- $\alpha$ together with IFN- $\gamma$ (both at $40 \mathrm{ng} / \mathrm{ml}$ ). Cells were incubated with cytokines for $48 \mathrm{~h}$. Black areas define negative control. (B) Mean fluorescence intensity (MFI). Average value of MFI in 5 independent experiments is shown. ${ }^{*}$ The difference between treated and control cells was statistically significant.
Flow cytometry is a very reliable method to investigate MUC1 content in the cellular membrane. This method confirmed the highest stimulatory effect of TNF- $\alpha$ on MUC1 protein incorporation into the cell membrane: $236 \%$ of stimulation was found. Similar to the data obtained in densitometry, in the presence of IFN- $\gamma$ and combined action of TNF- $\alpha$ and IFN- $\gamma$, the increase was lower, reaching $150 \%$ and $176 \%$, respectively, in comparison to control cells (Fig. 3).

\section{Effect of TNF- $\alpha$ on cell adhesion to ECM pro- teins (collagen and fibronectin)}

To determine the effect of TNF- $\alpha$ on HUVE cells adhesion to ECM proteins, the cells were treated for $6 \mathrm{~h}$ with 10 or $40 \mathrm{ng} / \mathrm{ml}$ of TNF- $\alpha$ and then adhesion test was performed. As shown in Fig. 4A incubation with TNF$\alpha$ does not change the adhesion of HUVECs to collagen type I in comparison to control cells. The employment of anti-MUC1 antibody caused increase in cells adhesion to collagen type I in control and TNF- $\alpha$ treated cells, in the same extent (about 20\%). In the presence of specific inhibitor of $\alpha_{2} \beta_{1}$ integrin, EC10, adhe- sion decreases similarly (about $30 \%$ compared to cells without EC10) in all tested groups of cells (Fig. 4A).

Treatment with TNF- $\alpha$ slightly enhanced adhesion of HUVECs to fibronectin, in a dose-dependent manner, compared with control cells $(9 \%$ and $17 \%$ of increase). In the presence of anti-MUC1 antibody, the adhesion of these cells to fibronectin increases about $7 \%$ (control cells), 6\% (T1) and 10\% (T2) compared to cells without antibody. Disintegrin VLO4, the blocker of $\alpha_{5} \beta_{1}$ integrin, has a greater effect on adhesion of cells incubated with TNF- $\alpha$ to fibronectin: adhesion was decreased $11.5 \%$ and $20 \%$, respectively for TNF$\alpha$ concentration $10 \mathrm{ng} / \mathrm{ml}$ and $40 \mathrm{ng} / \mathrm{ml}$, compared to cells without disintegrin (Fig. 4B).

\section{Discussion}

Membrane mucins are particularly important for providing a direct anti-adhesive barrier at the luminal surfaces of epithelia [22,23], protecting them against invasion from noxious organisms. Endothelia of blood vessels are a specialized form of epithelia, which have many similar functions to other epithelia. However, 
A

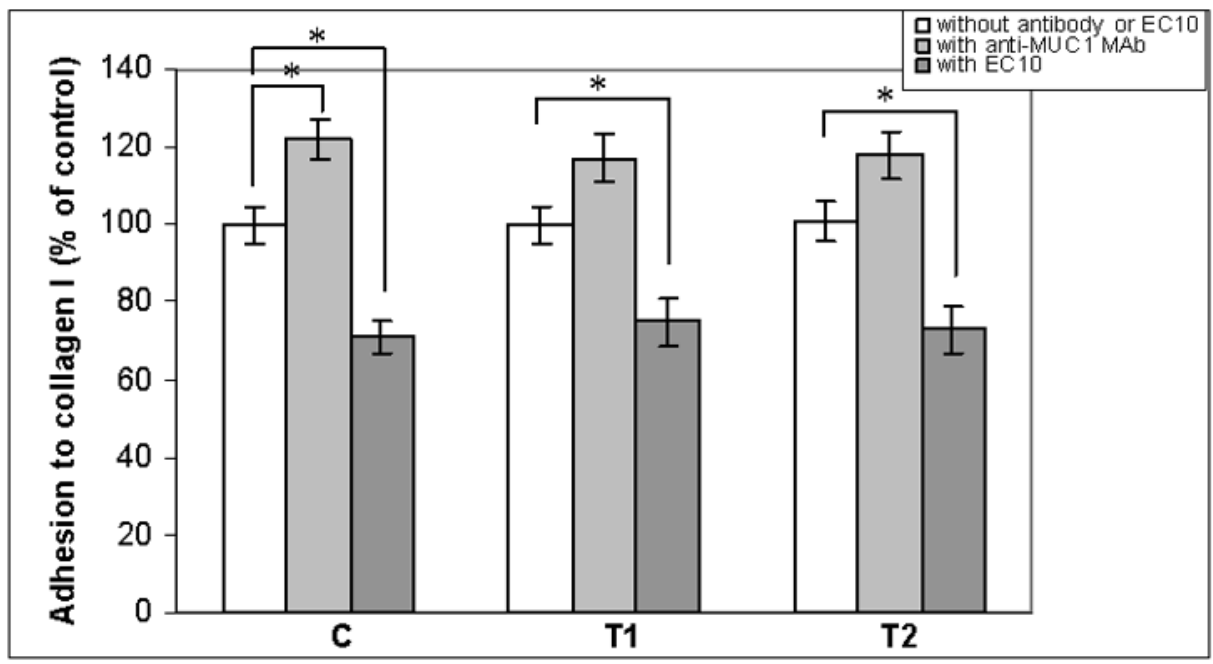

B

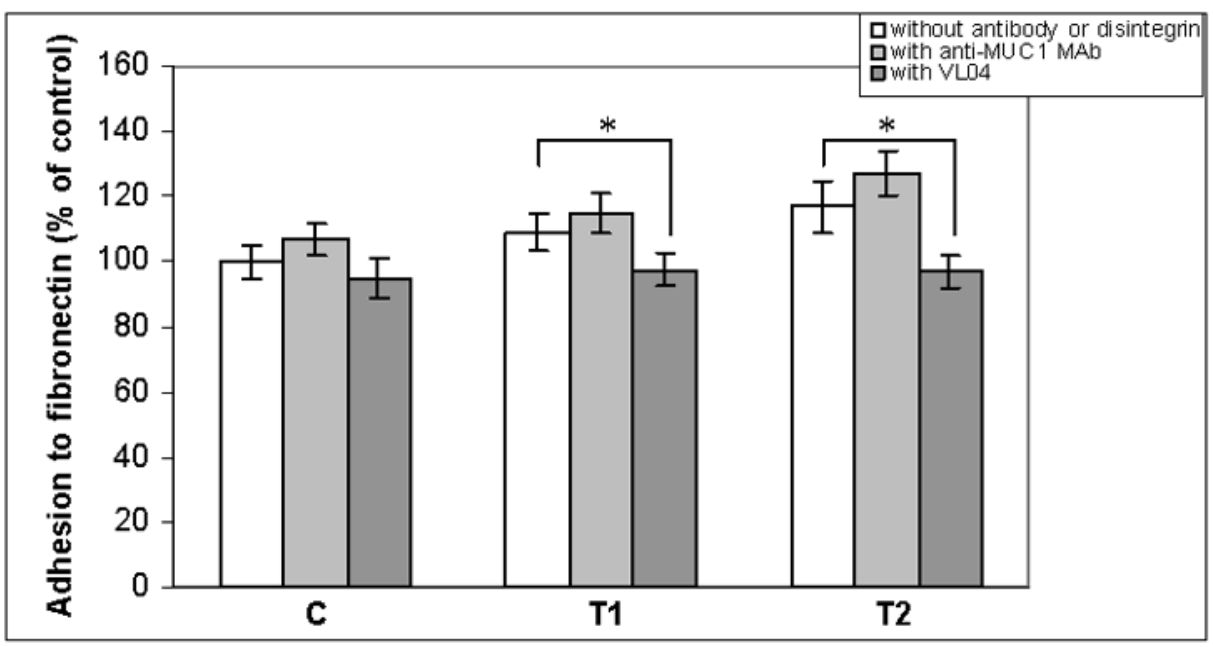

Fig. 4. Effect of TNF- $\alpha$ on cell adhesion to collagen type I (A) and to fibronectin (B).

Cells were incubated with TNF- $\alpha$ at concentrations of 10 and $40 \mathrm{ng} / \mathrm{ml}$ $\left(\mathrm{T}_{1}, \mathrm{~T}_{2}\right.$, respectively, $\mathrm{C}-$ control, non-stimulated cells) for 6 hours, then adhesion test was performed with anti-MUC1 MAb, with EC10 (for adhesion to collagen), with disintegrin VLO4 (for adhesion to fibronectin), or without these agents. Data are expressed as a mean $(\mathrm{n}=$ 4) \pm SD. ${ }^{*} p<0.05$, statistically significant differences compared with nonpreincubated cells from each group. mucins of the $M U C$ gene family have not been reported to play important roles in endothelial cells, despite of the fact that a non-adhesive luminal surface is critical in blood vessels. Instead, blood vessels are known to contain an array of different glycoproteins at their luminal surfaces [24]. Some of these, such as intercellular cell adhesion molecule (ICAM) and von Willebrand factor (vWF), are involved in cell-cell adhesion in the circulation [25]. Adhesion and anti-adhesion molecules play, among others, an important role in the interaction of tumor cells with vascular endothelial cells during tumor invasion and metastasis [26]. Vascular endothelial cells are also involved in angiogenesis, a critical process in wound-healing, inflammation, cancer development and embriogenesis.

In this study, we demonstrated that in human umbilical vein endothelial cells (HUVECs) MUC1 mucin protein can be synthesized and released/shed from cellular membrane. Electrophoresis and Western blotting analysis revealed transmembrane mucin
MUC1 in cell lysates and in culture medium of HUVECs. Based on the results of Western blotting, it can be claimed that MUC1 content in cellular medium is higher than in lysate and that mucin glycoforms, shed from cellular surface to medium, have greater molecular mass, probably in the effect of more extensive glycosylation, similarly to epithelial cells [27]. The quantitative assessment of MUC1 content in cell lysate was performed by radioactivity measurement. The presence of MUC1 on the surface of HUVE cells was also confirmed by flow cytometry.

In a number of epithelial cell types, including ovarian carcinoma [28], hematopoietic [29] and prostate tumor [21] cells, interferon- $\gamma$ has been shown to promote expression of MUC1. Tumor necrosis factor- $\alpha$ $(\mathrm{TNF}-\alpha)$ is also able to upregulate MUC1 expression in epithelial cells derived from airway, oral, breast, prostate and uterine tissues [10,21,30-33]. In prostate tumor cells [21], oral epithelial cells [31] and in normal breast epithelia and breast cancer cells [10], this 
effect has been shown to be synergistic with interferon- $\alpha$. For this reason, we decided to verify the effect of these cytokines on MUC1 biosynthesis in endothelial cells (HUVEC). Cytokines bind to specific receptors to activate associated tyrosine kinases that initiate downstream signaling. A signal transducer and activator of transcription (STAT) as well as nuclear factor kappa B (NF- $\mathrm{KB})$ response elements, located within the MUC1 promoter, apparently mediate the transcriptional induction of MUC1 by cytokines [10,34].

The expression of MUC1 on the surface of HUVECs was almost unaltered during a short-time (2$18 \mathrm{~h}$ ) treatment with TNF- $\alpha$, as measured by ELISA test. The extension to $48 \mathrm{~h}$ of incubation time with TNF- $\alpha$ resulted in an increase in the level of MUC1 antigen on the surface of cellular membrane (as measured by flow cytometry). The Western blotting method detected an increase in the expression of both MUC1 glycoforms: with high molecular mass above $205 \mathrm{kDa}$ and with lower molecular mass (116-205 kDa). Additionally, a decrease in molecular mass of a smaller MUC1 form was observed in the effect of TNF- $\alpha$ treatment. The molecular mass of this glycoform was unchanged after cell treatment with IFN- $\gamma$ alone or after combined action of these compounds. As proved by the measurement of radioactivity of $\left[{ }^{3} \mathrm{H}\right]$-glucosamine, bound to mucin oligasaccharides, TNF- $\alpha$ caused over a three-fold increase in the content of high molecular mass MUC1 form, compared to about a 2fold increase shown by Western blotting, where MUC1 polypeptide chain was detected. A possible explanation of this finding may be enhanced mucin glycosylation. We demonstrated a decrease in the level of sialic acid on cell surface of HUVECs after TNF- treatment. Since sialic acid residues are located on the non-reducing ends of glycoprotein oligosaccharide chains, therefore apparently longer oligosaccharide chains can be synthesized due to reduction in sialic acid content. On the contrary, $\mathrm{T}$ antigen content was not changed. It has been shown previously that in carcinoma cells the incomplete elongation of O-glycan saccharide chains leads to the expression of shorter carbohydrate structures such as Tn, sialyl-Tn, or T antigens, which are usually expressed on MUC1 mucin as their carbohydrate structures [35-37]. Thomsen-Friedenreich carbohydrate antigen (Gal $\beta 1-3$ GalNAc $\alpha 1-S e r / T h r-T F$ or T antigen), observed on the surface of endothelial cells, could play a role in the interactions of these cells with galectin-3, similarly to cancer cells [38].

Poor effect of short-time treatment with TNF- $\alpha$ on MUC1 expression was confirmed by adhesion test. Adhesion of TNF- $\alpha$-treated cells to collagen type I was unchanged while adhesion to fibronectin was slightly increased as compared to control cells. The results of adhesion test with anti-MUC1 antibody and with specific blockers of $\alpha_{2} \beta_{1}$ and $\alpha_{5} \beta_{1}$ integrins con- firmed the presence of these membrane proteins on HUVEC membrane surface. MUC1 mucin can exert an anti-adhesion effect, caused by steric hindrance of interactions between adhesion receptors and their ligands, and therefore after blocking of mucin by a specific antibody, an increase in adhesion was observed. On the other hand, blocking of adhesion receptors integrins, caused a decrease in adhesion to ECM proteins. As a result of HUVEC treatment with TNF- $\alpha$, the expression of $\alpha_{2} \beta_{1}$ was unaltered, since the reduction in adhesion after incubation with EC10 was the same in control and cytokine treated cells. On the contrary, the expression of $\alpha_{5} \beta_{1}$ integrin presumably rose after cytokine treatment and therefore the effect of this integrin blocking was higher in treated than in untreated cells.

In conclusion, we are the first to report that MUC1 transmembrane mucin is expressed in human umbilical vein endothelial cells and could be shed from cell surface to culture medium. We also show that mucin expression is stimulated by proinflammatory cytokines. These data indicate MUC1 presence on the cellular membrane of endothelial cells although the role of this glycoprotein in interactions with different cell types in physiological and pathological processes needs further investigations.

\section{References}

[1] Gendler SJ. MUC1, the renaissance molecule. J Mammary Gland Biol Neoplasia. 2001;6:339-353.

[2] Baldus SE, Engelmann K, Hanisch FG. MUC1 and the MUCs: a family of human mucins with impact in cancer biology. Crit Rev Clin Lab Sci. 2004;41:189-231.

[3] Andrianifahanana M, Moniaux N, Batra SK. Regulation of mucin expression: Mechanistic aspects and implications for cancer and inflammatory diseases. Biochim Biophys Acta. 2006;1765:189-222.

[ 4] Theodoropoulos G, Carraway KL. Molecular signaling in the regulation of mucins. $J$ Cell Biochem. 2007;102:1103-1116.

[5] Lightenberg M, Vos H, Gennissen A, Hilkens J. Episialin, a carcinoma associated mucin, is generated by a polymorphic gene encoding splice variants with alternative amino termini. J Biol Chem. 1990; 265:5573-5578.

[ 6] Gendler SJ, Lancaster C, Taylor-Papadimitriou J et al. Molecular cloning and expression of human tumor associated polymorphic epithelial mucin. J Biol Chem. 1990;265:1528615293.

[7] Gendler SJ, Spicer AP. Epithelial mucin genes. Annu Rev Physiol. 1995;57:607-634.

[ 8] Hanisch FG, Müller S. MUC1: the polymorphic appearance of a human mucin. Glycobiology. 2000;10:439-449.

[9] Lagow E, DeSouza MM, Carson DD. Mammalian reproductive tract mucins. Human Reprod Update. 1999;5:280-292.

[10] Lagow EL, Carson DD. Synergistic stimulation of MUC1 expression in normal breast epithelia and breast cancer cells by interferon-gamma and tumor necrosis factor-alpha. J Cell Biochem. 2002;86:759-772.

[11] Zhang K, Baeckstrom D, Brevinge H, Hansson GC. Secreted MUC1 mucins lacking their cytoplasmic part and carrying sialyl-Lewis a and $\mathrm{x}$ epitopes from a tumor cell line and sera of colon carcinoma patients can inhibit HL-60 leukocyte 
adhesion to E-selectin-expressing endothelial cells. $J$ Cell Biochem. 1996;60:538-549.

[12] Jung SE, Seo KY, Kim H, Kim HL, Chung IH, Kim EK. Expression of MUC1 on corneal endothelium of human. Cornea. 2002;21:691-695.

[13] Rounds S, Likar LL, Harrington EO et al. Nucleotide-induced PMN adhesion to cultured epithelial cells: possible role of MUC1 mucin. Am J Physiol Lung Cell Mol Physiol. 1999;277:L874-L880.

[14] Paszkiewicz-Gadek A, Porowska H, Anchim T, Wołczyński $\mathrm{S}$, Gindzieński A. Biosynthesis of MUC1 mucin in human endometrial adenocarcinoma is modulated by estradiol and tamoxifen. Gynecol Endocrinol. 2003;17:37-44.

[15] Laemmli UK. Cleavage of structural proteins during the assembly of the head of bacteriophage T4. Nature. 1970;227:680-685

[16] Yan LJ, Sohal RC. Gel electrophoretic quantitation of protein carbonyls derivatized with sodium borohydride. Anal Biochem. 1998;265:176-182.

[17] Strindhall J, Lundblad A, Pahlsson P. Interferon- $\gamma$ enhancement of E-selectin expression on endothelial cells is inhibited by monensin. Scand J Immunol. 1997;46:338-343.

[18] Paszkiewicz-Gadek A, Porowska H, Pietruczuk M, Haczyński J, Kisiel DG, Wołczyński S. Effect of estradiol and raloxifene on MUC1 expression and adhesive properties of Ishikawa cells. Oncol Rep. 2005;14:583-589.

[19] Calvete JJ, Moreno-Murciano MP, Theakston RD, Kisiel DG, Marcinkiewicz C. Snake venom disintegrins: novel dimeric disintegrins and structural diversification by disulphide bond engineering. Biochem J. 2003;372:725-734.

[20] Marcinkiewicz C, Lobb RR, Marcinkiewicz MM et al. Isolation and characterization of EMS16, a C-lectin type protein from Echis multisquamatus venom, a potent and selective inhibitor of the alpha2beta1 integrin. Biochemistry. 2000;39:9859-9867.

[21] O'Connor JC, Julian J, Lim SD, Carson DD. MUC1 expression in human prostate cancer cell lines and primary tumors. Prostate Cancer Prostatic Dis. 2005;8:36-44.

[22] Komatsu M, Carraway CAC, Fregien NL, Carraway KL. Reversible disruption of cell-matrix and cell-cell interactions by overexpression of sialomucin comlex. J Biol Chem. 1997;272:33245-33254.

[23] Komatsu M, Yee L, Carraway KL. Overexpression of sialomucin comlex, a rat homolog of MUC4, inhibits tumor killing by lymphokine-activated killer cells. Cancer Res. 1999;59:2229-2236.

[24] Cines DB, Pollak ES, Buck CA et al. Endothelial cells in physiology and in the pathophysiology of vascular disorders. Blood. 1998;91:3527-3561.
[25] McEver RP. Adhesive interactions of leukocytes, platelets, and the vessel wall during hemostasis and inflammation. Thrombosis Haemostasis. 2001;86:746-756.

[26] Song G, Ohashi T, Sakamoto N, Sato M. Adhesive force of human hepatoma HepG2 cells to endothelial cells and expression of E-selectin. Mol Cell Biochem. 2006;3:61-68.

[27] Huet G, Gouyer V, Delacour D et al. Involvement of glycosylation in the intracellular trafficking of glycoproteins in polarized epithelial cells. Biochimie. 2003;85:323-330.

[28] Clark S, McGuckin MA, Hurst T, Ward BG. Effect of interferon-gamma and TNF-alpha on MUC1 mucin expression in ovarian carcinoma cell lines. Dis Markers. 1994;12:43-50.

[29] Reddy PK, Gold DV, Cardillo TM, Goldenberg DM, Li H, Burton DJ. Interferon-gamma upregulates MUC1 expression in haematopoietic and epithelial cancer cell lines, an effect associated with MUC1 mRNA induction. Eur J Cancer. 2003;39:397-404

[30] Koga T, Kuwahara I, Lillehoj EP et al. TNF- $\alpha$ induces MUC1 gene transcription in lung epithelial cells: its signaling pathway and biological implication. Am J Physiol Lung Cell Mol Physiol. 2007;293:L693-L701.

[31] Li X, Wang L, Nunes DP, Troxler RF, Offner GD. Pro-inflammatory cytokines up-regulate MUC1 gene expression in oral epithelial cells. J Dent Res. 2003;82:883-887.

[32] Shirasaki H, Kanaizumi E, Watanabe K et al. Tumor necrosis factor increases MUC1 mRNA in cultured human nasal epithelial cells. Acta Otolaryngol. 2003;123:524-531.

[33] Thathiah A, Brayman M, Dharmaraj N, Julian JJ, Lagow EL, Carson DD. Tumor necrosis factor $\alpha$ stimulates MUC1 synthesis and ectodomain release in a human uterine epithelial cell line. Endocrinology. 2004;145:4192-4203.

[34] Gaemers IC, Vos HL, Volders HH, van der Valk SW, Hilkens J. A stat-responsive element in the promoter of the episialin/MUC1 gene is involved in its expression in carcinoma cells. J Biol Chem. 2001;276:6191-6199.

[35] Hollingsworth MA, Swanson BJ. Mucins in cancer: protection and control of the cell surface. Nat Rev Cancer. 2004;4:45-60.

[36] Springer GF. T and Tn, general carcinoma autoantigens. Science. 1984;224:1198-1206.

[37] Springer GF. Immunoreactive $\mathrm{T}$ and $\mathrm{Tn}$ epitopes in cancer diagnosis, prognosis, and immunotherapy. J Mol Med. 1997;75:594-602.

[38] Yu LG. The oncofetal Thomsen-Friedenreich carbohydrate antigen in cancer progression. Glycoconj J. 2007;24:411-420.

Submitted: 27 January, 2010 Accepted after reviews: 25 April, 2010 